\title{
An instrumental set up for seed germination studies with temperature control and automatic image recording
}

\author{
Pedro C.N. Teixeira*, José A. Coelho Neto, Humberto Rocha and Juracy M. de Oliveira \\ Centro de Pesquisa do Rio de Janeiro, Fundação Mokiti Okada, Rua Itabaiana, 74, Grajaú, 20561-050 Rio de Janeiro, RJ, Brasil. \\ *Corresponding author: fmopqrio@cpmo.org.br
}

Received: 27 April 2007; Returned for revision: 13 June 2007; Accepted: 09 July 2007

\begin{abstract}
This paper describes a new instrumental methodology proposed for the study of seed germination which can be applied to germination physiology, agriculture and forest restoration. This instrument performs the recording of images of germinating seeds through the use of a flat-bed scanner coupled to a computer, where a specific program commands the capture of these images at predetermined time intervals. These images are archived for posterior analysis. The device allows the collection of data and the elaboration of germination curves with high accuracy. Furthermore, the device permits the study of seed germination over a broad range of temperatures as well as the easy application of chemical agents to the seeds in order to study their influence on the germination process. Lactuca sativa seeds were used in this study as an experimental model. Germination curves were plotted at different temperatures in order to evaluate the device for experimental work. This paper also presents a methodology of statistical analysis that supports the reliability of this equipment.
\end{abstract}

Key words: digital image, Lactuca sativa, scanner, Siegel's test, thermal gradient tables

Dispositivo para estudos de germinação com controle de temperatura e registro automático de imagem: Este artigo descreve uma nova metodologia instrumental para o estudo de germinação de sementes aplicável à fisiologia da germinação, agricultura e a restauração de florestas. Este dispositivo registra imagens de sementes em germinação mediante o uso de um "scanner" acoplado a um computador, onde um programa específico comanda a captura dessas imagens para intervalos de tempo pré-determinados. Estas imagens são arquivadas para posterior análise. Este dispositivo permite a coleção de dados para a elaboração de curvas de germinação de modo particularmente acurado, em que a germinação das sementes pode ser realizada para uma larga faixa de temperatura; além disso, abre-se a possibilidade de aplicação fácil de agentes químicos nas sementes, no sentido de estudar a influência desses agentes no processo de germinação. Sementes de Lactuca sativa foram usadas como modelo experimental. Foram estabelecidas curvas de germinação para diferentes temperaturas, no sentido de avaliar nosso dispositivo em trabalho efetivo. Este artigo apresenta também uma metodologia de análise estatística que garante a confiabilidade do dispositivo ora descrito.

Palavras-chave: imagem digital, Lactuca sativa, mesa de gradiente térmico, "scanner", teste de Siegel

\section{INTRODUCTION}

The methods currently used in the study of seed germination under controlled conditions, with regard to research in botany and plant physiology, as well as the evaluation of seed potential for forest recovery and agriculture in its broader sense, are based on direct visual observation. This frequently requires the use of a magnifying glass or a stereomicroscope, and the manipulation of seeds to measure individually parameters such as seed and seedling size. In standard procedures seeds are placed on germination trays which are usually kept in climatized cabinets at previously 
established temperatures, over thermal gradient tables or other thermally controlled devices (Halldal and French, 1958; Larsen, 1965; Barbour and Racine, 1967; Fox and Thompson, 1971; Grime and Thompson, 1976; McLaughlin et al., 1985; Grime et al., 1989) or over thermal gradient blocks (Labouriau, 1977; Labouriau and Cavalcanti, 1996). The visual monitoring is carried out at pre-determined time intervals and the corresponding data registered in logbooks or similar registration media.

Currently available instrumentation is unable to follow and observe seed germination in a continuous mode without permanent human attention. This sometimes requires the involvement of more than one seed analyst, mainly during the periods when the seed population presents an increase in its germination. These procedures require the periodic removal of seeds from the cabinets for visual monitoring and this imposes uncontrolled disturbances of the temperature and humidity conditions. The current experimental methods of seed germination studies suffer from several others disadvantages. For example: (i) human visual observations are prone to misjudgment due to the large seed population or the time interval between the first and the last observation can be relatively long, thus inducing errors in the computation of time parameters and also in the observations of modifications which may occur along this time interval; (ii) the necessarily small number of seeds in each experiment that an experimenter can manipulate and observe in a reliable way; (iii) the difficulty of handling in a reasonably short time interval a sufficient number of experiments that can offer solid statistics; and (iv) the increasing possibility of contamination with microorganisms from the air due to frequent seed manipulation. Generally, these instruments cannot analyze a reasonable number of seeds in a single operation, thus restricting good statistical evaluation or the rapid collection of data for agricultural use.

From these considerations the following reasoning emerges: these difficulties and limitations could be circumvented through the use of a device able to record the images of germination as it evolves using a fairly large number of seeds in an automated procedure together with the digital analysis of these images and a sound statistical treatment of the quantitative data. Descriptions of instruments presenting these characteristics have been published in recent years in the specialized literature (Dell'Aquila, 2006), and some instruments use as an image capture recorder a flat-bed scanner or a high resolution video camera coupled to a computer. The majority of these instruments are devised to use digitized images for the analysis of certain characteristics, such as radicle protrusion, seedling size, seed shape, seed color and seed defects. Some of these instruments use a flat-bed scanner to capture images of seeds sown on substrates layered at the bottom of Petri dishes (Geneve and Kester, 2001) or a video camera (Dell'Aquila et al., 2000) directly coupled to a germination chamber which can be acclimatized.

According to the concepts outlined above, this paper presents an instrumental methodology where visual observation can be substituted by a flat-bed scanner or a video camera mounted over the germination chamber. The seed population images captured at pre-established time intervals are sent to a computer where they are archived for posterior analysis. It is also possible to eventually or systematically make observations from the monitor screen of the whole seed population under investigation and to print these images as a serial recording. The automated observation of the seed population allows a retroactive analysis from the very beginning of the process including the possibility of repetitive analysis by different observers to check how far an eventually tendentious practice of observation can affect the results. This methodology has not only applications in plant physiology and crop seed evaluation, but is also a useful tool for studies in thermobiology, principally in view the possibility of working over a broad temperature range in a single experiment, with strict control of each pre-established temperature. The distribution of each temperature value over the germination plate can be preestablished in a gradient fashion if so desired. In this sense the apparatus represents an improvement in relation to thermal gradient tables.

With this system it is possible to achieve shorter time intervals between consecutive images captures, so that a greater number of points in a time sequence can be obtained (each point representing a chronological state of germination). This permits greater accuracy in the representation of the corresponding graphical data, allowing a more precise interpretation of the results.

In this paper, we present the above proposed apparatus and methodology, with a generalized 
appraisal of its potential use in the study of seed germination. Lactuca sativa seeds were sown in the experimental device and submitted to a broad temperature range, and the germination behavior of the whole population recorded along the process, as described above. With this procedure the following issues were checked: (i) experimental reproducibility of the system supported by a stringent control of temperature; (ii) germination homogeneity over the different regions on the germination support surface or between different germination blocks; and (iii) capacity of this system to produce a large volume of germination data at programmed time intervals, thereby allowing the construction of germination curves with great accuracy and reliability.

\section{MATERIAL AND METHODS}

Seeds: Lactuca sativa cv Grand Rapids seeds (specially furnished free of fungicide) were used, purchased from Feltrin, State of Rio Grande do Sul, Brazil (www. sementesfeltrin.com.br).

Seed Germination: Seeds selected with weights between 1.0 and $1.7 \mathrm{mg}$ (with precision of $\pm 0.3 \mathrm{mg}$ ) were prehydrated for $2 \mathrm{~h}$ on soaked paper in Petri dishes before their transfer to the moist paper used on the germination support. This paper was printed with indelible ink in order to form an array of vertical thick black bars crossed perpendicularly by thin lines (Figure 1) resulting in 272 small cells. Each cell has, therefore, the form of a white square with a black band at each side. A single seed is positioned on each white area, so that the point where the radicle will appear is above the black band at the edge of the white area. Once radicle protrusion occurs, its pale yellow image contrasts sharply against the black band. The seeds, before germination on the moist paper, were kept for $24 \mathrm{~h}$ at $3.0^{\circ} \mathrm{C}$ in an attempt to improve synchronization through a cold stratification process (William and Vivian, 1980; Yamaguchi et al., 2004). In this paper, the event considered as indicative of germination is radicle protrusion and elongation (the botanical criterion).

Equipment description: The system is essentially composed of four modules (see Figure 2); $1^{\text {st }}$ module germination chamber (A); $2^{\text {nd }}$ module - germination blocks (thermostatically controlled) with a metallic plate used as the support bed for the moist paper which receives the seeds $(\mathrm{B}) ; 3^{\text {rd }}$ module - transparent window with thermal insulation properties through which the seed germination images (radicle protrusions) are picked up, while the seeds are maintained in a condition of constant temperature and humidity $(\mathrm{C}) ; 4^{\text {th }}$ module $-\mathrm{a}$

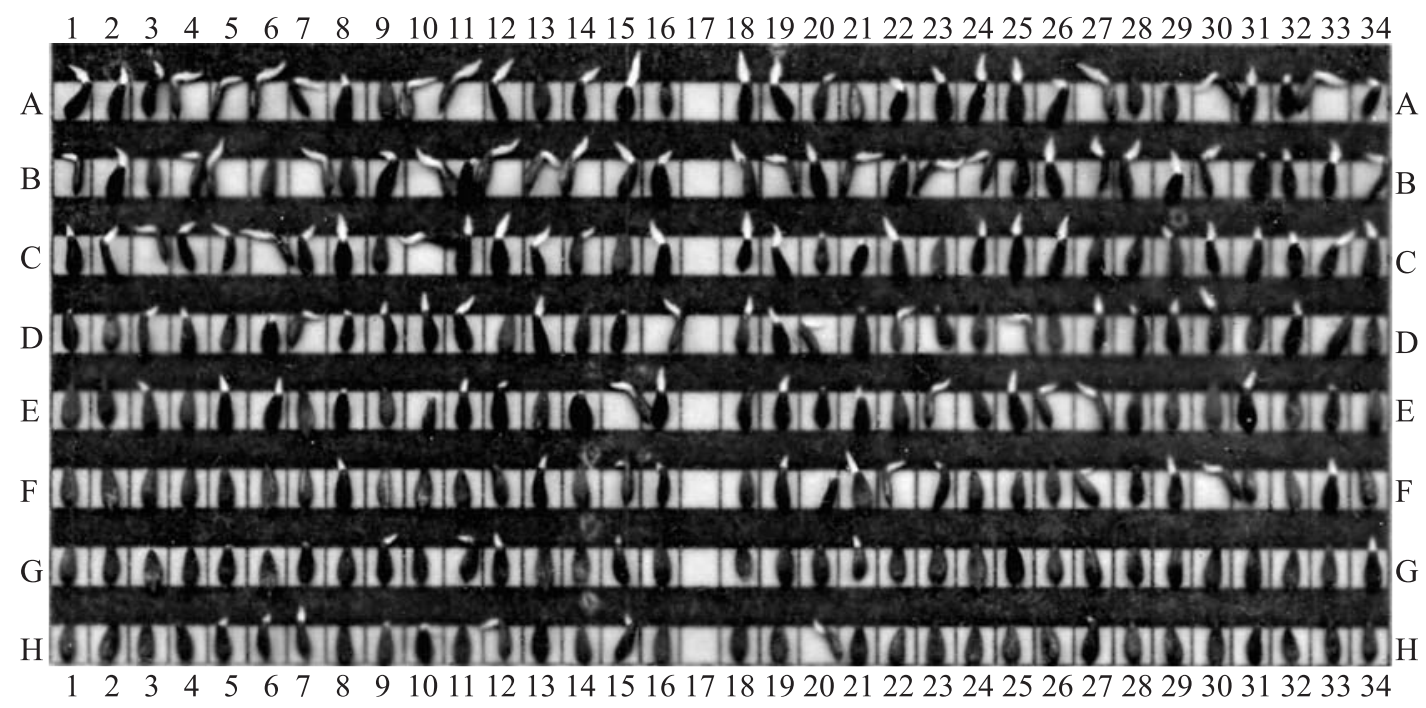

Figure 1. Top view of the germination chamber. Observe the regular matrix distribution of seeds on the array of white cells and the protruding radicles over the adjacent black bands. 


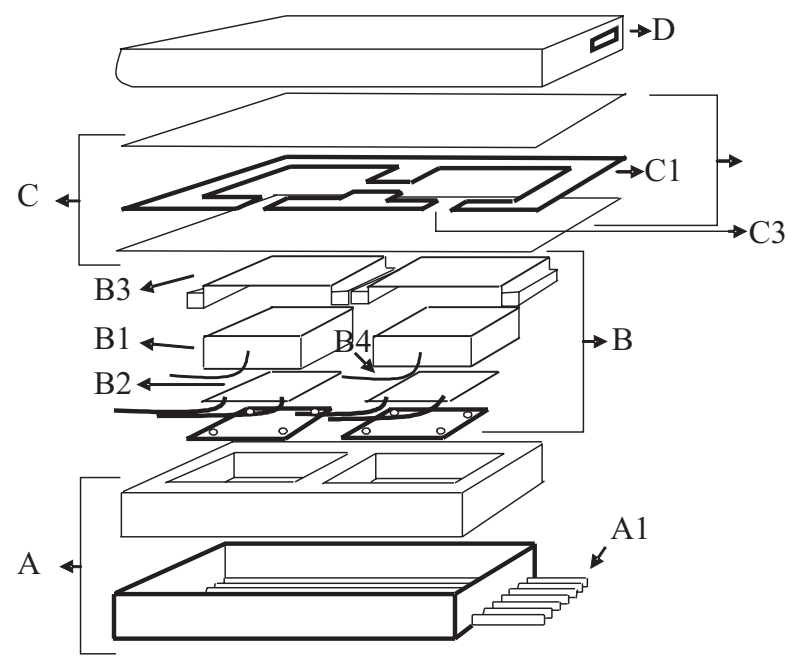

Figure 2. General view of the germination system.

device to capture images: a flat-bed scanner coupled to a computer for the automatic image record (D).

The first module is a compartmentalized box. This box has a rectangular shape at the open top and is constructed with material of low thermal conductivity, high resistance to heat and mechanical stress (for example, polyurethane-coated acrylic or high-density polystyrene foam). The model here presented (Figure 2) contains two compartments (this number can be increased). The inner compartments of this box have the same volume and are equally thermally insulated, its upper edge slightly above the surface of the thermostatic blocks. This slight difference in height allows the proper positioning of the transparent double wall window (C) avoiding excessive or unwanted pressure against the seeds. The compartmentalized box cavities receive the germination blocks (B).

To facilitate gas exchange between the outer air and the inner compartments a small opening was drilled at one side of these compartments. The thermostatic blocks (B1) are constructed with aluminum and are in direct communication with the water filling the germination box (A). The germination supports (blocks) function as heat conductors homogenizing the heat distribution along the whole surface where the seeds are placed. The temperature control in these aluminum blocks (B1) is obtained as a consequence of the thermal equilibrium attained through the interaction of a cold and a hot source. The cold source is the water (coming from a thermostatic bath) circulating into the germination box through stainless steel tubes (A1). This box is filled with water in order to establish thermal contact between the blocks and the cold source. The hot source (B2) is an electronically controlled heater resistor. The final temperature adjustment is obtained through the power control of the heating resistance in function of a difference in temperature between the aluminum block and the temperature adjusted by the operator. This difference was monitored by a COEL temperature controller model 4300, with PID loop control, receiving its analogic voltage signal input from a type $J$ thermocouple (B4) and sending an analogic current signal output (from 4 to $20 \mathrm{~mA}$ ) to a Loti phase angle type controller model $\mathrm{BC}$, which controls the delivery of power.

The second module is comprised essentially of a set of germination blocks and an equal number of germination support beds. The germination support beds (B3) are made of thin stainless steel sheets that fit over the blocks and are held firmly by screws to the body of the blocks. The support beds have two reservoirs alongside, containing water or any desired solution, for the maintenance of the humidity level in the moist paper or eventually to receive some chemical dissolved in the germination water.

The third module is constructed with a double wall transparent glass window, to facilitate image capture from within the germination chamber, besides functioning as a heat insulator, and avoiding water condensation. This module is constructed by the insertion of a cork gasket (C1) between two glass plates (C2). This gasket is made of a cork sheet of similar size and shape as the glass plates and has two rectangular windows cut out for seed visualization. The space between the two glass plates within each window area functions as an insulating air layer. Channels are also cut in the cork sheet (C3) to make two opposing air ducts connecting openings at the edges of the gasket to the inner part of each air chamber. The whole set up rests on top of a rubber gasket glued to the upper edge of the germination chamber enclosure.

Air at a slightly higher temperature than the environment in the germination chamber is introduced into the insulating air chambers by a centrifuge fan, through the inlet and the outlet air ducts described above, thereby preventing the condensation of water 
droplets in the windows that can occur at higher temperatures.

The fourth module consists of a flat-bed scanner (Genius model Color Page/EP - optical resolution 400 dpi). The scanner is positioned directly over the third module, so that its scanning window face lies parallel to the seed supports. This is only possible if the scanner unit is placed in an upside-down position. To do so, the supporting rods were adapted to fit the scanner unit horizontally over the germination chamber.

The computer coupled to the fourth module was used to capture and store the images received at regular time intervals from the flat-bed scanner. Image capture automation is performed by the task schedule software, namely Scheduler Professional for Windows Version 3.13 (www.splinterware.com) or any other program specifically developed for this purpose.

Image record: The captured images were processed by the program Page Image (Prolab Tech. Co., Ltd.) and the recorded images were archived with the Tagged Image File Format (.tif) at a resolution of $300 \mathrm{dpi}$ (black and white images).

Computer configuration: Pentium II (Intel), $233 \mathrm{MHz}$, RAM 64MB, containing a 40 GB hard disk.

Statistics and graphical analysis: The software BIOESTAT 4.0 (Ayres et al., 2005) was used for statistical analysis. The Excel software was applied to optimize the germinated seed counting procedure. Graphical plotting and analysis were carried out with the aid of Origin 7.0 (OriginLab Corporation).

Evaluation of the germination curves at a set of chosen temperatures and the homogeneity of the experimental data: A set of sequential images was captured at predetermined time intervals, each image representing a picture of the seed population germination stage. The quantitative analysis of each image can be performed by visual observation on the computer monitor. The observation of each germination event in each image from the set corresponding to an experiment is registered in code on a printed spreadsheet containing blocks of cells whose layout is identical to that of the printed grid on the germination paper. To represent the time corresponding to the germination events as a code, index numbers are used to identify the chronological order of germination events observed. These numbers are integer numbers starting from 1, which corresponds to an event that was observed in the image registered at the time when the first scanning was performed. The index number increases in unitary steps, corresponding to the sequence number of each scan. Thus, index number 2 represents a germination event observed in the image registered at the time of the second image collection, and so on. For example, if a germinated seed appears on the monitor screen at a determined position, in the image collected at the first observation time, the number 1 is recorded in the cell corresponding to the position of this seed in the printed spreadsheet. Completing this counting for all the times (pictures) the data from the resulting spreadsheet are reproduced on an Excel spreadsheet, keeping the same layout correspondence between spreadsheet cells and positions on the germination plate as shown in Figure 3 .

Within the scope of statistical analysis of the results there was a need to evaluate average and dispersion values for germination counting with time along the germination curve. For this, the resulting spreadsheet was subdivided into six regions, each region with 44 seeds (the shape of the regions is represented in Figure 3, label A). For each germination time, the calculation of the arithmetic mean and the SD were performed and these values used to represent the average and dispersion estimates, respectively.

For the elaboration of germination curves, the counting corresponding to a specific captured image was located within each of the six regions on the block. Taking in account the counting data of all blocks for all indexes, germination counting was plotted against time to obtain the germination curve.

To verify possible differences between the two blocks and among the different regions of each block, a statistical treatment was applied in order to assure that the factors which are responsible for germination (or have any effect on it) are perfectly distributed over the whole seed population. In other words, the system can be checked this way for the creation of regional artifacts in the germination data.

To verify the data homogeneity among the different regions of each block, the data blocks reproduced on the Excel spreadsheet were subdivided into 34 regions with eight cells per region (a typical layout of the region is 
shown in Figure 3, label B), and the mean germination time was computed for each region. Assuming that all the regions were equivalent, it can be expected that the mean germination time of the regions along the block surface would be homogeneously distributed. This means that the data set corresponding to the mean germination time of the regions should behave as a random data set. The 34 regions were indexed according to their positions in an ordered sequence following an orientation in rows or in columns on the Excel spreadsheet (Figure 3). Data differences among regions may occur due to influences that behave as gradients along the main directions of the array of seeds; thus, the sequence numbering of the regions may be performed along rows or along columns. Doing so, each one of these indexes was paired with the computed mean time value corresponding to the region. To each mean germination time, an ordinal time rank number was assigned indicating its order on a temporal scale, so that number 1 was assigned to the lowest time value, number 2 to the following, and so on. Then it was possible to establish a link between each region position and its time rank. A table was constructed (Table 1) to show the relationship between position indexes (considering sequences along rows or along columns, as stated before) and those indexes belonging to the time rank. To these sets of numbers Siegel's randomness test was applied, in order to evaluate how the mean germination time values are distributed over the block's surface, whether in a random or in a deterministic fashion. Siegel's randomness test may be best applied to a binary rank sequence (for example, with 0's and 1's). The result of the test corresponds to an evaluation parameter for the random distribution of 0 's and 1's in the sequence, where there were $\mathrm{N}_{0}$ values 0 and $\mathrm{N}_{1}$ values 1 in the binary sequence. The practical application of this test to the data produced in our experiments was possible through the use of the following procedure: attributing the value 0 to time rank values equal or smaller than 17 , and value 1 to time rank values higher than 17 it was possible to create a sequence of binary indexes correlated with the 34 regions (see "classification" in Table 1). The procedure described above generated a sequence of 17 rank indexes 0 , and 17 rank indexes $1\left(\mathrm{~N}_{0}=17\right.$ and $\left.\mathrm{N}_{1}=17\right)$. Searching within this sequence for subgroups constituted by repetition of one of the rank indexes ( 0 or 1$)$ it was possible to compute the

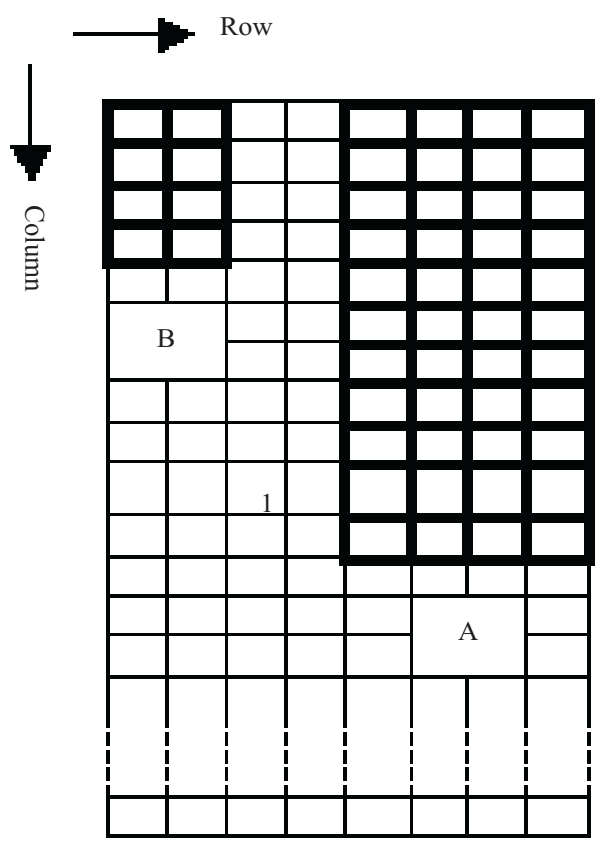

Figure 3. Representation of the Excel spreadsheet where the germination events are numerically presented. A and B represents the region created to perform the statistical analysis (see Material and Methods, item 5). The number 1 in this spreadsheet (which is incomplete and only presented here as an example) indicates the place where the first event was registered (the first germination).

Table 1. Siegel's test data, as applied to germination events (see Material and Methods, item 5).

\begin{tabular}{|c|c|c|c|c|c|}
\hline \multicolumn{6}{|c|}{ Germination Block } \\
\hline \multicolumn{3}{|c|}{ Row ordered regions } & \multicolumn{3}{|c|}{ Column ordered regions } \\
\hline \multicolumn{3}{|c|}{ Germination } & \multicolumn{3}{|c|}{ Germination } \\
\hline Region & $\begin{array}{l}\text { Time } \\
\text { rank }\end{array}$ & Classification & Region & $\begin{array}{r}\text { Time } \\
\text { rank }\end{array}$ & Classification \\
\hline 1 & 21 & 1 & 1 & 21 & 1 \\
\hline 2 & 11 & 0 & 2 & 16 & 0 \\
\hline 3 & 8 & 0 & 3 & 33 & 1 \\
\hline 4 & 12 & 0 & 4 & 18 & 1 \\
\hline 5 & 16 & 0 & 5 & 22 & 1 \\
\hline 6 & 7 & 0 & 6 & 34 & 1 \\
\hline 7 & 1 & 0 & 7 & 26 & 1 \\
\hline$\vdots$ & $\therefore$ & $\vdots$ & $\vdots$ & $:$ & $\vdots$ \\
\hline 31 & 19 & 1 & 31 & 30 & 1 \\
\hline 32 & 6 & 0 & 32 & 23 & 1 \\
\hline 33 & 32 & 1 & 33 & 24 & 1 \\
\hline 34 & 28 & 1 & 34 & 6 & 0 \\
\hline \multicolumn{3}{|c|}{ Analysis Parameters } & \multicolumn{3}{|c|}{ Analysis Parameters } \\
\hline N0 & N1 & $\mathrm{R}$ & N0 & & $\mathrm{R}$ \\
\hline 17 & 17 & 15 & 17 & & 12 \\
\hline
\end{tabular}


$\mathrm{R}$ value, which must represent the total number of these subgroups. With this value the application of the Siegel's test was possible (as quoted by Santana and Ranal, 2004).

\section{RESULTS}

It can be observed in Figure 4 that with the apparatus and methodology proposed, a great number of points was obtained over short time intervals such that the gaps between the points of the germination curves are negligible. This fact permits the construction of a reliable sigmoid-type curve which overall represents the seed germination curves. For temperatures below $8.4^{\circ} \mathrm{C}$ and above $28.0^{\circ} \mathrm{C}$ the dispersion data, represented by the set of error bars, permits a sharp distinction between curves at two temperatures differing by not more than $2.0^{\circ} \mathrm{C}$. From $10.0^{\circ} \mathrm{C}$ to $25.0^{\circ} \mathrm{C}$ this distinction was possible only if the difference in temperature was at least of $4.0^{\circ} \mathrm{C}$.

The germination curves presented in Figure 5 clearly
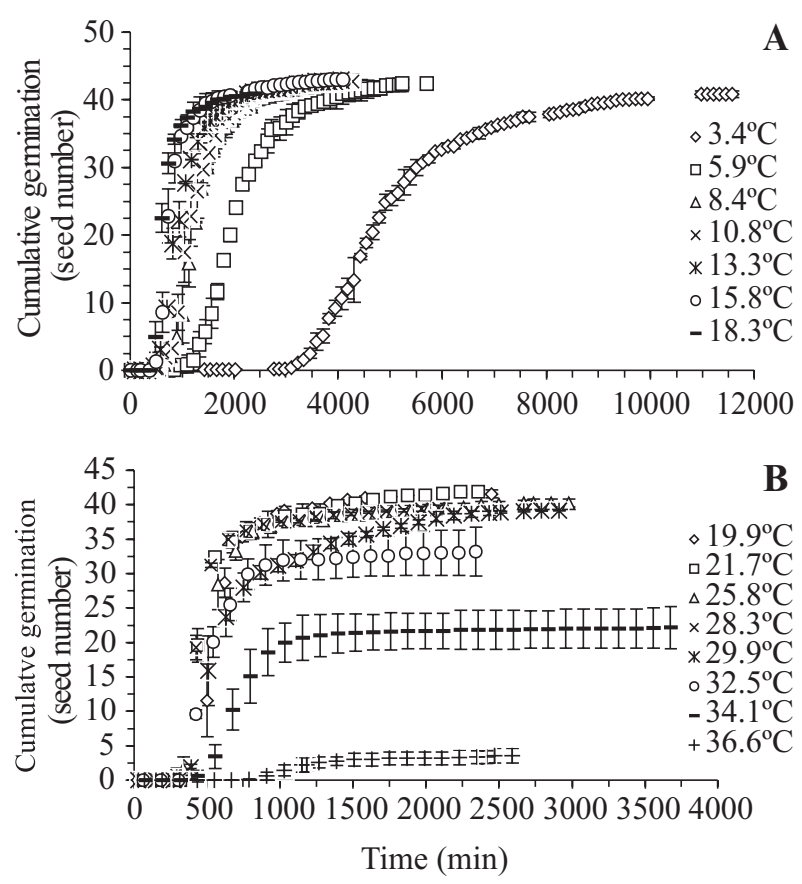

Figure 4. Germination curves of Lactuca sativa seeds where each point represents the mean value of germination data for A and B blocks. Errors for each point are represented by the small vertical bars. In $\mathbf{A}$ : seed germination at $3.4^{\circ} \mathrm{C}, 5.9^{\circ} \mathrm{C}, 8.4^{\circ} \mathrm{C}, 10.8^{\circ} \mathrm{C}, 13.3^{\circ} \mathrm{C}, 15.8^{\circ} \mathrm{C}$, and $18.3^{\circ} \mathrm{C}$. In $\mathbf{B}$ : seed germination at $19.9^{\circ} \mathrm{C}, 21.7^{\circ} \mathrm{C}$, $25.8^{\circ} \mathrm{C}, 28.3^{\circ} \mathrm{C}, 29.9^{\circ} \mathrm{C}, 32.5^{\circ} \mathrm{C}, 34.1^{\circ} \mathrm{C}$, and $36.6^{\circ} \mathrm{C}$. indicate the similarity of germination behavior on these two blocks, so that these data sets are practically indistinguishable. This is true, not only for each temperature, but also for each time, as indicated by the excellent agreement between paired data corresponding to both blocks. In other words the germination behavior is practically the same for these two blocks.

Considering the evaluation of Siegel's test, the value $\mathrm{R}$ was computed as stated before for each temperature, for every row and column for the two blocks. The R values indicate the degree of randomness. According to Siegel's test, for a distribution where $\mathrm{N}_{0}=17$ and $\mathrm{N}_{1}=17$, the expected $\mathrm{R}$ values for a random sequence must be between 11 and 25. In Figure 6 a plot is shown of the $\mathrm{R}$ values computed with the data from all the experiments available, performed over a broad range of temperatures and considering positional sequencing of values both in the row sense and column sense. The dashed lines represent the values of expectation limits mentioned above. It is evident that the experimental $\mathrm{R}$ values obtained were well grouped around the most probable value of 17 , comprised mostly within the expectation limits, with the exception of two points.

This assertion was also tested using another statistical test. Considering the former proposed division of the experimental data in six regions, the data set corresponding to these regions on the Excel spreadsheet, for both germination blocks, were submitted to a nonparametric variance analysis, the Kruskal-Wallis

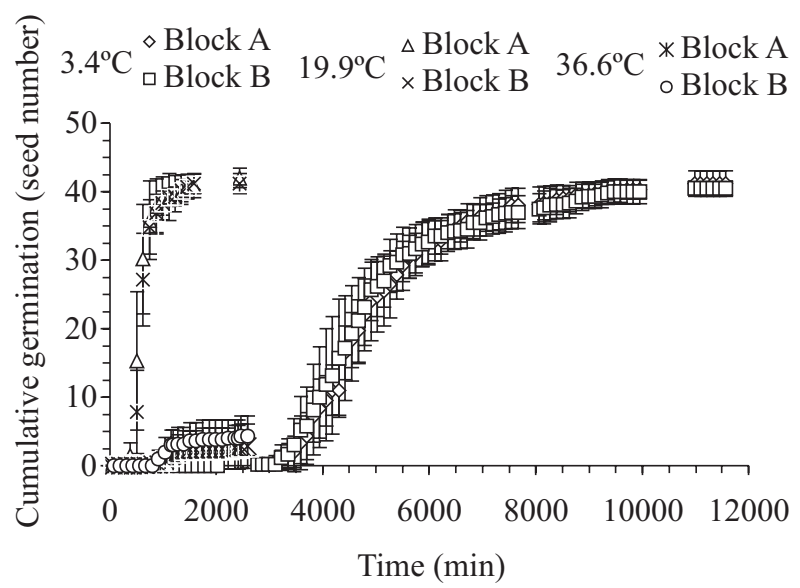

Figure 5. Germination curves relative to block $\mathrm{A}$ and block $\mathrm{B}$ for germination temperatures of $3.4^{\circ} \mathrm{C}, 19.9^{\circ} \mathrm{C}$ and $36.6^{\circ} \mathrm{C}$. 


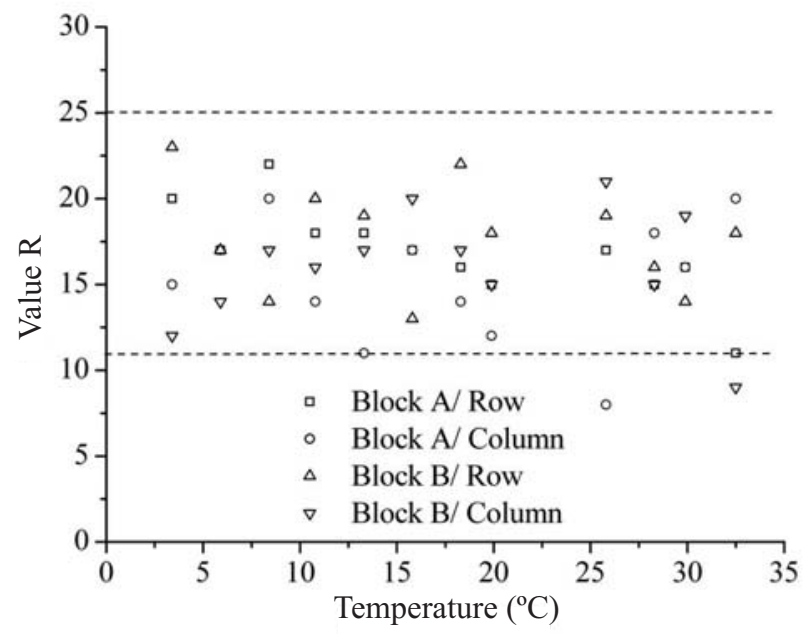

Figure 6. Experimental values of R (Siegel's test) for germination on block A and block B analyzed in rows or columns for different temperatures. The dashed lines determine the upper and the lower limits of reliability for $\mathrm{R}$ values.

test (Ayres et al., 2005), where every region on each block was matched with the $\mathrm{n}-1$ remaining regions. This test was applied to the data corresponding to $3.4^{\circ} \mathrm{C}$ and $19.9^{\circ} \mathrm{C}$ (depicted in Figure 5). Due to the small number of seeds germinating at $36.6^{\circ} \mathrm{C}$, this test could not be applied in a reliable way to the data computed at this temperature. This test produced, for the data obtained at $3.4^{\circ} \mathrm{C}$ and $19.9^{\circ} \mathrm{C}$, Kruskal-Wallis probability values of 0.0034 and 0.0016 , respectively, indicating a highly homogeneous behavior of the whole set of germination data for all the regions on each block and the same behavior occurring between the two blocks. These results of Siegel's test and the Kruskal-Wallis test cited above are in very good agreement, with the expected random nature of germination data distribution.

\section{DISCUSSION}

The instrumental system presented here for the study of seed germination represents a novel device and a quite efficient tool for this purpose. The description of this device and its associated methodology clearly indicates its versatility and its several advantages in comparison with the current methods of seed germination analysis as pointed out in the Introduction. These advantages are based mainly on its high level of automation, where the image capture by the image sensor is performed in a precisely controlled manner at scheduled time intervals. As a consequence the procedure incorporates a set of practical advantages: (i) the recording and storage of germination data is such that the retroactive analysis of the data is possible, this being performed by direct visualization on the monitor screen or in a digitized form by a computer program (an impossible task when using conventional methods based on visual observation); (ii) the possibility of image capture at any previously chosen instant and at closer time intervals, thus resulting in the minimization of gaps between experimental points in the germination curves as well as sharper and highly reproducible curve profiles, in contrast to the curves constructed by conventional methods; and (iii) the possibility of elaborating a program to determine the time interval between consecutive image captures to optimize the use of the scanner, thereby avoiding unnecessary image captures, with the further possibility of controlling the observation window width. Additionally, during the period when the fastest germination rate is expected, the time between image captures may be reduced to an extent that is practically impossible with direct visual observation. Furthermore, the higher fidelity in the analysis of the seed population as a whole results in the construction of curves richer in information and greater in accuracy. Besides these analytic advantages there is an operational advantage worthy of note: the possibility of quick and easy water supply replenishment without great disturbances of the environment of the experiments. This procedure also permits the administration of several chemicals to the seeds, including phytohormones, when the reactions elicited by these agents can be observed in real time.

With regard to temperature control, the equipment described here carries out this task individually in each germination block through the use of separate electronic thermostats. This kind of temperature control allows great versatility in the assignment of predetermined temperatures to each block. This also permits the increase or decrease of the temperature of all blocks or a particular block during an experiment. These features are particularly advantageous for research in thermobiology.

When using scanners corresponding to paper size A4 in the apparatus here described, two germination blocks per scanner may be used. Working with, for example 20 blocks at the same time with 20 sets of different 
conditions, at least 10 scanners must be used. To obviate this question special scanners could be developed for this purpose, capable of scanning greater lengths and consequently the length of the germination chamber could be extended accordingly to hold a greater number of germination blocks. Larger scanners using the set up proposed here could accommodate seeds of medium or greater size.

A minor limitation of this equipment that will be overcome in a model now under construction is the difficulty in visualization of the seed population because of water condensation at temperatures above $36.0^{\circ} \mathrm{C}$.

Some features of this apparatus that deserve special emphasis are its reliability and the consistency of the results. This was demonstrated through the careful application of statistical methods of analysis to the computed data, assuring the absence of artifacts which could induce errors in data interpretations.

Further aspects of this apparatus and its associated methodology are worthy of consideration. Radicle protrusion, as observed here, can be an advantageous tool for the evaluation of seed vigor, taking into account the botanical criterion for this important parameter and this can be complemented with the measurement of radicle growth rate. Such computer-aided image evaluations have been proposed and performed by several authors (Hoffmaster et al., 2003; Oakley et al., 2004; Teixeira et al., 2006; Dutt and Geneve, 2007) who point out the absence of subjectivity and shorter work time when compared with the several conventional methods of visual observation. Computeraided image assessment can be carried out in an easier, fast and reliable way by the instrument and methodology here presented.

Acknowledgments: The authors wish to acknowledge Feltrin Importadora de Sementes, Farroupilha, Rio Grande do Sul, for the kind gift of the Lactuca sativa seeds, selected and free of fungicides.

\section{REFERENCES}

Ayres M, Ayres MJ, Ayres DL, Santos AS (2005) BioEstat 4.0. Aplicações Estatísticas nas Áreas das Ciências Biológicas e Médicas. $4^{\text {th }}$ ed. Sociedade Civil Mamuirá, MCT, Imprensa Oficial do Estado do Pará, Belém.

Barbour MA, Racine CH (1967) Construction and performance of a temperature-gradient bar and chamber. Ecology 48:861-863.

Dell' Aquila A, van Eck JW, van der Heijden GWAN (2000) The application of image analysis in monitoring the imbibition process of white cabbage (Brassica oleracea L.) seeds. Seed Sci. Res. 10:163-169.

Dell' Aquila A (2006) Computerized seed imaging: a new tool to evaluate germination quality. Comm. Biom. Crop Sci. 1:20-31.

Dutt M, Geneve RI (2007) Time to radicle protrusion does not correlate with early seedling growth in individual seeds of Impatiens and Petunia. J. Amer. Soc. Hort. Sci. 132:283-436.

Fox DJC, Thompson PA (1971) A thermo-gradient bar designed for use in biological studies. J. Exp. Bot. 22:741-748.

Geneve RI, Kester ST (2001) Germination using computeraided analysis of digital images from a flat-bed scanner. HortScience 36:1117-1120.

Grime JP, Hall W, Hunt R, Neal AM, Ross-Fraser W, Sutton F (1989) A new development of the temperaturegradient tunnel. Ann. Bot. 64:279-287.

Grime JP, Thompson K (1976) An apparatus for measurement of the effect of amplitude of temperature fluctuation upon the germination of seeds. Ann. Bot. 40:795-799.

Halldal P, French CS (1958) Algal growth in crossed gradients of light intensity and temperature. Plant Physiol. 33:249-252.

Hoffmaster AL, Fujimura K, Macdonald MB, Bennett MA (2003) An automated system for vigor testing threeday-old soybean seedlings. Seed Sci. Technol. 31:701-713.

Labouriau LG (1977) A thermal gradient block for germination experiments. Rev. Bras. Biol. 37:295-305.

Labouriau LG, Cavalcanti RB (1996) Um bloco de gradiente térmico de fácil construção para experimentos termobiológicos. Rev. Bras. Fisiol. Veg. 8:149-156.

Larsen AL (1965) Use of thermogradient plate for studying temperature effects on seed germination. Proc. Int. Seed Test. Assoc. 30:861-868.

McLaughlin NB, Bowes GR, Thomas AG, Dyck FB, Lindsay TM, Wise RF (1985) A new design for a seed germinator with 100 independently temperature controlled cells. Weed Res. 25:161-173.

Oakley K, Kester ST, Geneve RL (2004) Computer-aided digital image analysis of seedling size and growth rate for assessing seed vigor in Impatiens. Seed Sci. Technol. 32:837-845. 
Santana GD, Ranal MA (2004) Análise da Germinação. Um Enfoque Estatístico. Ed. Fundação Universidade de Brasília, Brasília.

Teixeira EF, Cícero SM, Neto DD (2006) Análise de imagens digitais de plântulas para avaliação do vigor de sementes de milho. Rev. Bras. Sem. 28:150-167.

William JV, Vivian KT (1980) Studies of the mechanism of enhancement of phytochrome dependent lettuce seed germination by prechilling. Plant Physiol. 66:220-224.

Yamaguchi Y, Ogawa M, Kuwahara A, Hamada A, Kamyia Y, Yamaguchi S (2004) Activation of gibberellin biosynthesis and response pathways by low temperature during inhibition of Arabdopsis thaliana seeds. Plant Cell 16:367-371. 